established scientifically to information at present only obtainable in newspaper reports. Emphasis need not be laid on the obvious advantages of a film sound-record over an ordinary mechanically produced gramophone record. Combinations of picture films and ordinary gramophones have been frequently tried without success sufficient to ensure their survival in practice. The difficulty, of course, mainly arises from the impossibility of preserving synchronism between a gramophone record and a film the length of which is gradually but inevitably shortened by the repairing of frequent breakages. With the sound-record also upon a film, the appropriate adjustment can always be made, especially in the ideal case where a single film bears both picture- and sound-records, side by side, under which conditions it becomes automatic. The arrangement of two separate films, run both in recording and reproducing on the same shaft, has, according to the Times report, been adopted by $\mathrm{Mr}$. Bergland; $\mathrm{Mr}$. Grindell Matthews, on the other hand, announces that he has been able, in spite of the small space available, to secure the advantages of a single film, a newspaper reproduction of which is given. In neither case are the reported details complete enough to indicate the actual mechanism employed. One point of somewhat curious interest seems, however, to be fairly definitely established. An examination of the printed reproduction of Mr. Grindell Matthews's film shows that the soundrecord is of what may be called the ordinary type -i.e. it consists of the trace of transverse movements of a spot of light on a moving film, so familiar in oscillograph and other wave-motion records. A talk which the author was fortunate enough to have recently with Prof. Arrhenius, who was present at the first demonstration of the new Swedish talking pictures, made it clear that Mr. Bergland also relies on this same plan. It is not easy to see how such transverse records lend themselves to effective sound-reproduction. On the face of it, they would appear to be distinctly inferior for this purpose to the records described and illustrated in this article, and details of the manner in which the selenium is actuated will be awaited with interest.

We have yet to learn also by what mechanism synchronisation has been effected. For, although the principle involved is very simple, and the general method of procedure is quite obvious, there have no doubt arisen in practice details which present serious difficulties. We may hope to hear before long what these are and how they have been surmounted.

\title{
The Oppau Explosion.
}

$T^{H}$ $\mathrm{E}$ directors of the Badische Anilin- und Sodafabrik state in the Zeitschrift für Angewandte Chemie for October 4 that the explosion at the nitrogen fixation works at Oppau on September $2 \mathrm{r}$ took place in a store containing about 4500 ton's of ammonium sulphate nitrate. They explain that, before the war, only sulphate of ammonia was made at Oppau; ammonium nitrate was manufactured during the war, and since then, mixtures of ammonium nitrate and potassium chloride, and more recently ammonium nitrate and sulphate for use as fertilisers. They definitely state that no ammonium nitrate was present in the works at Oppau at the time of the explosion, and go on to say that while the explosive nature of ammonium nitrate is well known, this feature can be completely eliminated by mixing it with potassium or sodium chlorides; the double salt, $2 \mathrm{NH}_{4} \mathrm{NO}_{3} \cdot\left(\mathrm{NH}_{4}\right)_{2} \mathrm{SO}_{4}$, had also been shown to be non-explosive when pure as well as when it is produced on the works scale. They proceed to quote evidence as to the non-explosive character of this salt from the fact that it gives no distension in the Trauzl block test, when exploded by means of a detonator containing 2 grams of mercury fulminate, and in substantiation of its innocuous character they adduce the fact that in factories producing it no accident has occurred for a number of years, when explosives have been applied to it for the purpose of breaking up blocks of the mixed salts which have set hard. They deny that
Oppau was completely destroyed, and say that the portion of the factory devoted to the production of ammonia from the air and of ammonium sulphate is comparatively uninjured, so that the manufacture could be started again, and they end with an assurance that the production of ammonia by high pressure as carried out by the Badische Anilin- und Sodafabrik has nothing whatever to do with the explosion.

It may be remarked in connection with this statement that no reference is made to experimental work on the explosive character of their product on a larger scale than by attempting to fire it by a No. 8 detonator in a Trauzl block. It is known, however, to explosive technologists that ammonium nitrate responds only feebly to such a detonator, but that it can be brought up to detonation by a suitably chosen initial impulse.

The Times of October I 2 gives an account of some very remarkable evidence brought out at a sitting of the German Parliamentary Committee appointed by the Reichstag to inquire into the explosion. It appears from the evidence that the process was being worked intensively and without adequate chemical control, and it is stated that in the preparation of the ammonium sulphate nitrate the ammonium nitrate was not always dissolved, but passed on to the store as such. Evidence was also given as to the fact that blasting was resorted to for the purpose of breaking up the hardened mass, and in a further report, published in the

NO. 27 I 3, VOL. IO8] 
Times of October 17 , it is stated that this blasting was sub-let to a firm of contractors and was done by men on piece-work.

There appear to be at least three commissions investigating the accident : one, appointed by the Reichstag, another by the Bavarian Government, and a third by the Workmen's Council of the Oppau factory, and it is gathered that there is some conflict as to the powers and status of these commissions. An adjournment of the inquiry has evidently been made, but it is not clear as to whether this is for the purpose of obtaining further evidence on the danger of blasting, or, as is suggested by the writer of an article in the ChemikerZeitung of October 6, on danger that may arise from heating up of the mass through the liberation of nitric acid from ammonium nitrate by the acid held as an impurity in the ammonium sulphate. With regard to the latter point, it is stated that the representatives of the factory are taking a continuous record of the temperature of the remaining stock, which amounts to 8 , ooo tons, with the object of flooding it if any considerable rise occurs.

In view of the importance of ammonium nitrate and other salts of ammonia for fertiliser purposes on the very largest scale, it is to be sincerely hoped that every endeavour will be made by the InterAllied Commission of Control to obtain the final report of the German Parliamentary Committee, together with a record of any experiments conducted to elucidate the cause of the explosion.

\section{The Age of the Earth. ${ }^{1}$}

\section{By the Right Hon. Lord Rayleigh, F.R.S.}

\section{THE subject which we have met to consider to-day is encumbered with past controversy.} It cannot be denied, I am afraid, that exponents of particular views in the past have laid too much emphasis on their own particular way of looking at the problem without making enough allowance for human fallibility. I shall try, so far as possible, to avoid this pitfall. There has been a tendency on all sides for specialists in one branch of science to consider themselves free to disregard evidence drawn from a class of considerations with which they are not familiar. I am sure that this is not the road to truth. In attempting a problem of this kind, when we seek to plumb into the depths of time, far beyond human experience, we cannot afford to neglect evidence drawn from any quarter, even if it is not the kind of evidence which we find it most congenial to contemplate. A parallel case is that of a jury of plain men in a murder trial. They may know nothing of medical jurisprudence, postmortem examinations, and so on. They may even consider the subject repellent; but that does not exempt them from the duty of fully considering and weighing such evidence to the best of their ability. The witnesses in the trial have, however, to limit themselves to matters with which they are personally conversant. I will try to give my evidence within these limits.

The phrase "age of the earth," though rather vague, is perhaps definite enough for our purpose. What we want to know is, how long has the earth's surface been fitted for the habitation of living beings? or, alternatively, how long has it taken to accumulate the known series of geological formations? These questions are not the same, but I do not think that we shall need to insist on the distinction this morning.

Lord Kelvin's arguments depended on attempts to limit the length of time during which the

1 Contributions to a joint discussion of the Sections of Mathematical and Physical Science, (ie ,logy. Zonlogy, and Botany of the British Association at Edinburgh on September 13. earth's surface temperature could have remained substantially the same as at present, and he attacked this problem from two different points of view. In the first place, he attempted to set a limit of time to the duration of the sun's heat; and secondly, from consideration of the earth's internal heat, he argued back to the time when the surface was too hot for the presence of living beings. I have heard a suggestion that there is some mutual inconsistency in these two lines of argument-consideration of the sun's heat makes the past temperature too low; consideration of the earth's heat makes it too high-but I do not think that this criticism is more than superficially plausible. The point was rather that from either of these arguments a condition widely different from the present would be reached, and therefore that, even if there were some unrecognised flaw in one of the arguments, the other would stand. Possibly, looking back into the remote past, a condition of the earth's surface is imaginable where the mean temperature was much the same as at present, heat. coming from the earth's interior in compensation for a diminished radiation from the sun; but I feel sure you will all agree with me that we cannot get more time by special pleading of this kind. The fossiliferous rocks have, without doubt, been accumulated under conditions of solar radiation not essentially different from the present. One simple consideration is that the plants in the coal measures obviously had green leaves, and that these could not function without a full allowance of solar radiation.

We have then to consider whether Lord Kelvin's arguments can stand in the light of present knowledge. I think we must admit that they cannot.

First, as regards the earth's heat, it is now generally known that the premises of Lord Kelvin's calculation, carefully particularised by him, are upset by the discovery of radio-active substances in the earth. In 1906 I made a deter-

No. 2713 , VOL. IO8] 